\title{
تربية الطفولة المبكرة على أساس المعهل الإسلامي
}

\author{
Yusuf Ali Tantowi*, Syihabuddin, Hilman Taufiq A.
}

\section{Universitas Pendidikan Indonesia, Indonesia}

*E-mail:yusuf_tantowi@upi.edu

\begin{abstract}
Abstrak. Usia dini merupakan masa yang sangat penting sebagai landasan karakter bagi manusia, semua instrumen utama manusia terbentuk. dari kecerdasan bingga perkembangan psikis, sehingga masa ini disebut dengan masa keemasan. Raudatul Athfal Nurul Ansor Bandung merupakan salah satu PAUD yang memiliki keunikan dalam pembelajaran, karena berbasis Pesantren. harus memiliki kekhasan dalam pembentukan karakter religius. Penelitian ini bertujuan untuk mendeskripsikan pendidikan anak usia dini $\mathrm{R} A$, agar dapat menginspirasi institusi lain dalam pengembangan pendidikan anak usia dini. Pendekatan yang digunakan adalah deskriptif kualitatif dengan teknik yang digunakan dalam pengumpulan data, yaitu: 1) teknik observasi, 2) teknik wawancara, dan 3) teknik dokumentasi. Hasil akhir dari program ini dapat dikatakan cukup berhasil walaupun belum optimal. Salah satunya karena beberapa siswa masih belum menguasai materi sesuai target yang telah ditetapkan oleh sekolah.
\end{abstract}

Kata Kunci: Pesantren, PAUD, Pendidikan, Raudatul Athfal.

الملخص. العمر المبكر هو عصر مهم كأساس الشخصية للناس. تتشكّل كلّ الأدوات البشرية

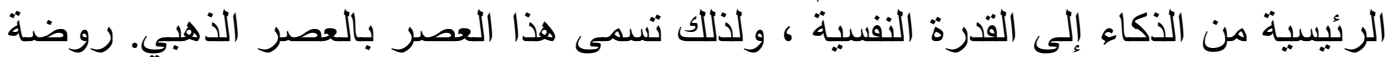

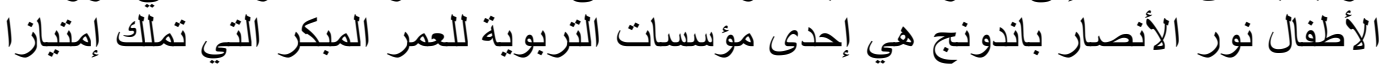

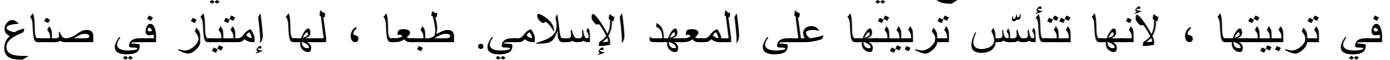

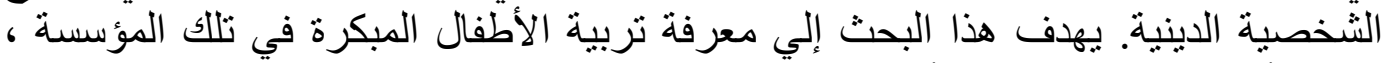

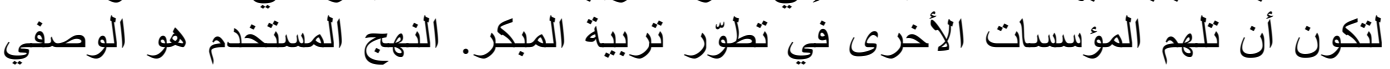

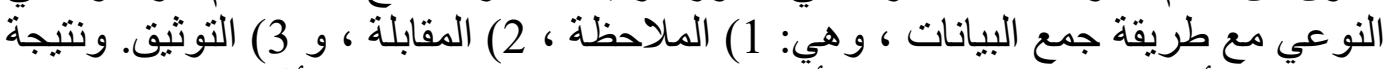

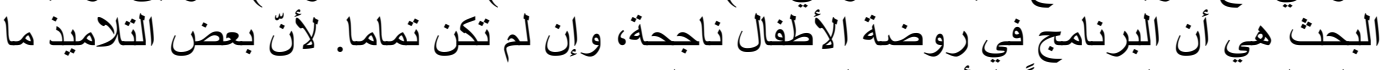
زالوا لم يتقنوا المادة وفقًا لتلأهداف التهونة التي حددته المدرسة.

الكلمات المفتاحية: المعهد الإسلامي ، تربية الأطفال المبكر ، تربية ، روضة الأطفال. 
ولادته. يمكن أن يعمل التصميم في المنزل أو التمقيا

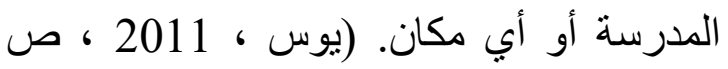
هذا اليوم ، حقائق حالة الأطفال تثير القلق. تأثير 19). يحدث نمو الأطفال وتطورهم في هذه النه

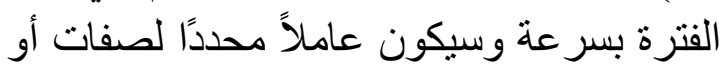

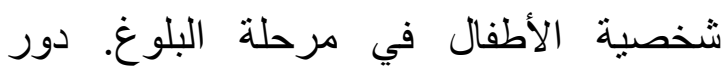

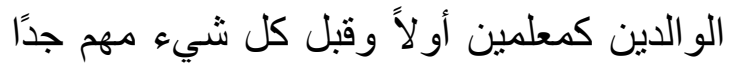
لتحقيق أقصى استفادة من هذه الفترة ، و ولا يمكن

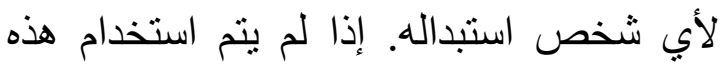

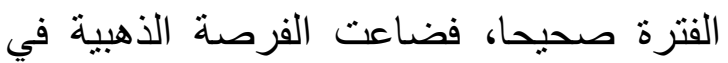

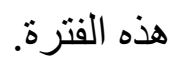
3087 حالات العنف للأطفال ، ومنها 852

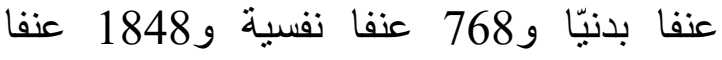

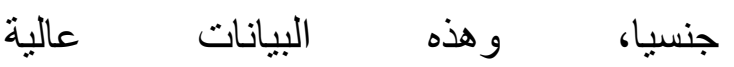
(kemenpppa.go.id) و هذا يثبت أن التربية في مرحلة الطفولة

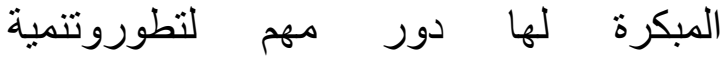
الأطفال.خاصة في فترة العصر الذهبي. تسمى

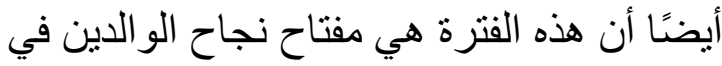

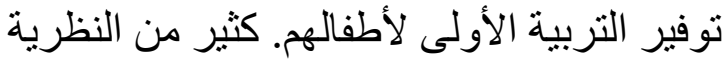

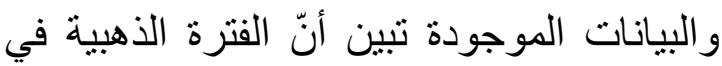
العصر المبكر تتطور جميع إمكانات الأطفال

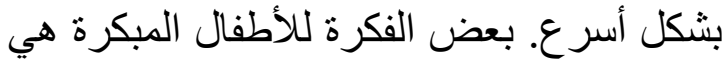
فترة الاستكثاف، وفترة التشرة التحديد، و والفترة الحساسة، وفترة اللعب، وفترة العصيان الأول

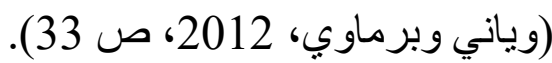
العمر المبكر هو الفرصة الذهبية للأطفال

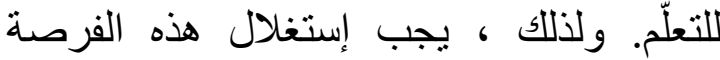

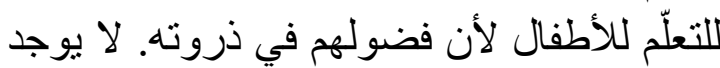

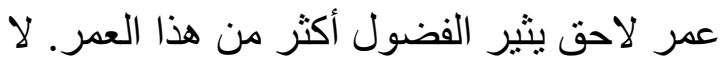
يركز توجيه التعلم في مرحلة الأطفال المبكرة الألئ

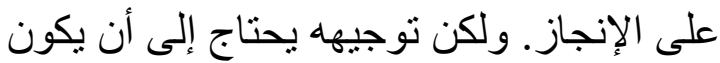

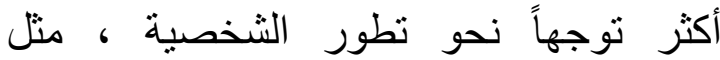
المو اقف و الاهتمام بالتعلم و الإمكانات و القدر ات اتل

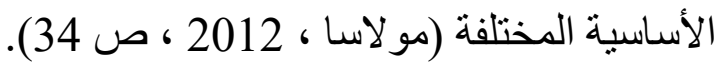
تكون البيئة من العناصر المهمة المؤثرة على لئل تتمية الأطفال. يثد تصميم البيئة بطريقة خاصنة البرة

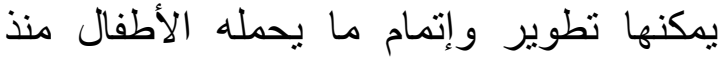

يميل الأطفال الذين ينشأون في أسرة وبيئة متناغمة إلى أن يكونوا أطفالًا صالحين. في هذه الأن

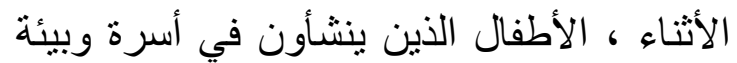

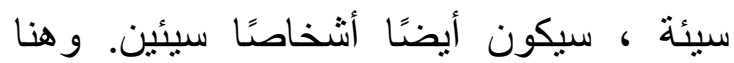

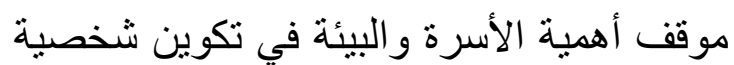

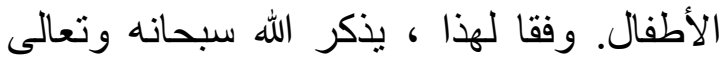

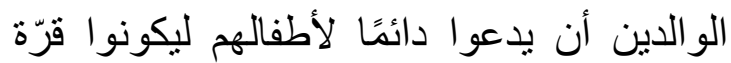

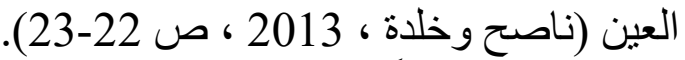

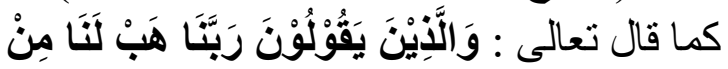

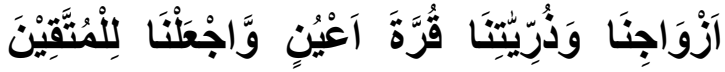

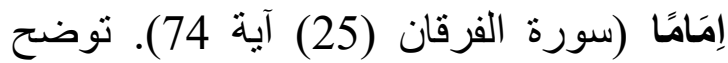

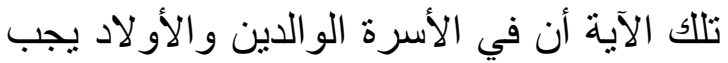

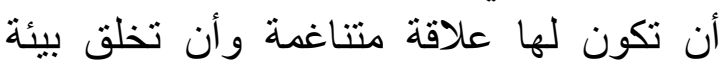

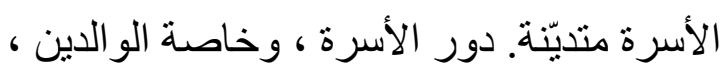

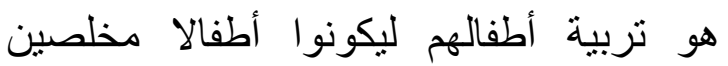

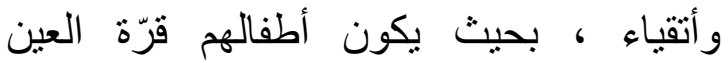

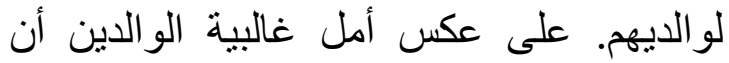
يكون لديهم أطفال يمكن أن يكونو ا قرّة العين.

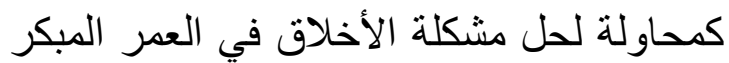

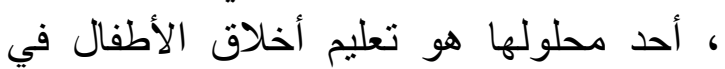

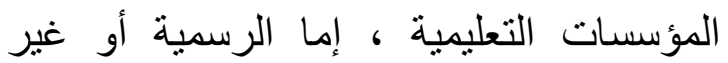

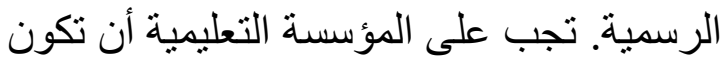

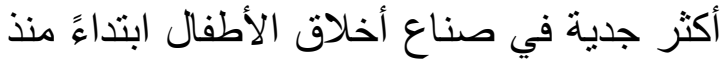
سن المبكر. إحدى المؤسسات التعليمية غير الاطنية الرسمية التي تركز على التربية الدينية هي التئية غيري

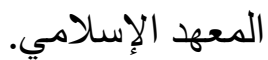




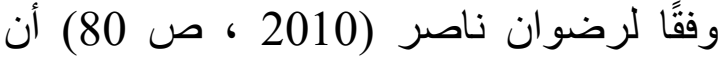

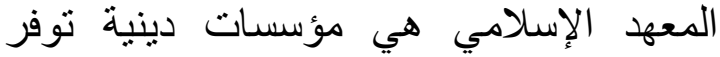
التعليم والتربية وتطوير العلم الدينية الإسلامية

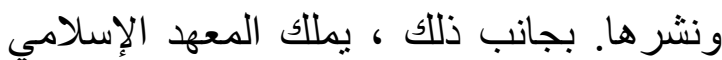

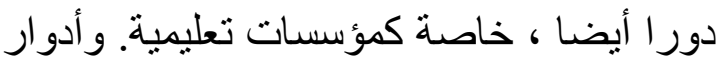

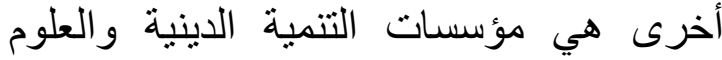
و التدريب وتنمية المجتمع ، وفي نفس الوقت

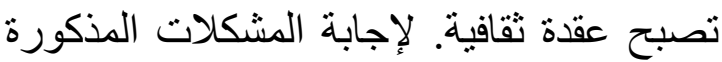

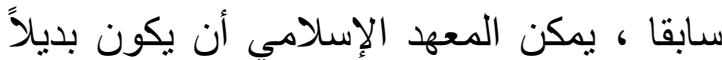

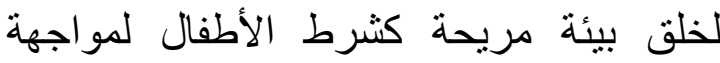

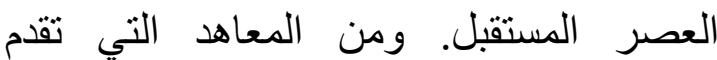
التوجيه الديني للأطفال المبكرة هي معهد نور التهي الأنصار الإسلامي كمؤسسات تقوم منذ 1984

م ، ويثق بها المجتمع لاكتساب العلوم الدينية.

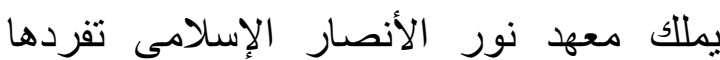

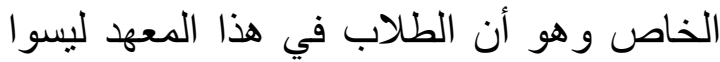
فقط من المقيمين ولكن هنالك طلاب ليسوا مقيمين أيضا أو مصطلحه "ngalong".

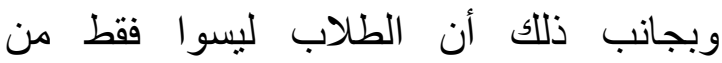

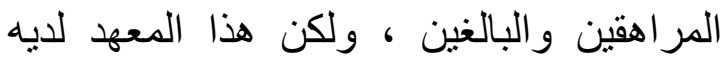

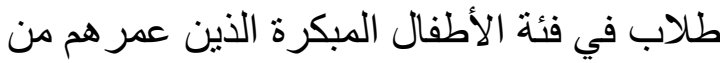

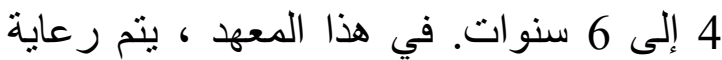
الأطفال المبكرة تحت رعاية مؤسسة شبه الكيه

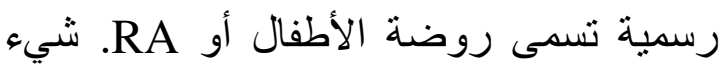

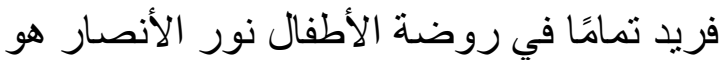

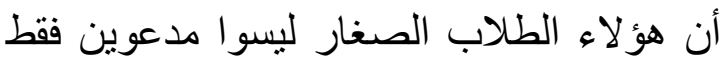

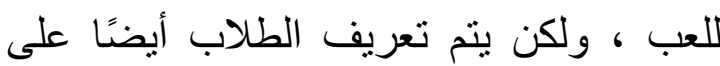

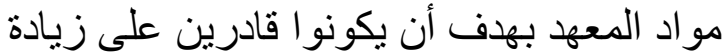

قيم الثخصية الجيدة لدى الطلاب الصغنار.

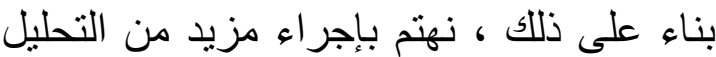
في تأثثر تربية الأطفال المبكرة على أساء

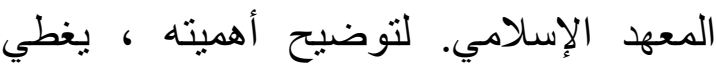
تركيز هذا البحث عملية تعلم الأطفال المبكرة الإنهي

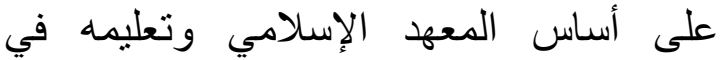
روضة الأطفال نور الأنصار ، وحصولهيا ونعائه
يستخدم هذا البحث أسلوب نوعي بطريقة وصفية. أما تقنيات جمع البيانات في هذا البحث

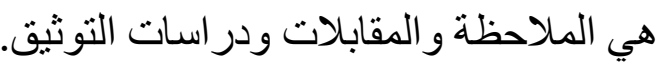
بجانب ذللك ، نهتم أيضًا بإجراء بلاء بحث حول الاستفادة من الفترة الذهبية للطفل من خلاء خلادل

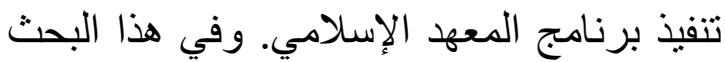
، نستخدم المنهج الكمّي. لا يستعمل هذا البحثي

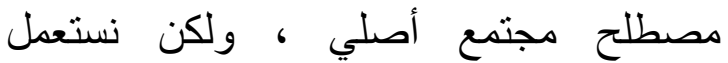
"social situation" أو الحالة الإجتماعية المكونة من ثلاثة عناصر ، و هي المكن و الفاعل

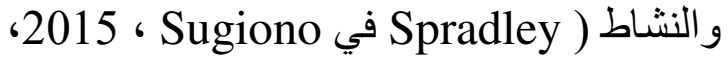
ص 297) (297). يعمل هذا البحث في روضة الأطفال نور الأنصار التي تقع في شارع محمود رقم 73 ، 73 ، ، 3 RW 3 RT هرجا أسيح ، باندونج. كان سبب قيام البحث هناك، لأن الباحث رئيس ومعلّم في تلك روضئ

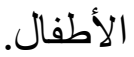
في مرحلة الإعداد ، نعمل بحثا أوليا حيث عشنا

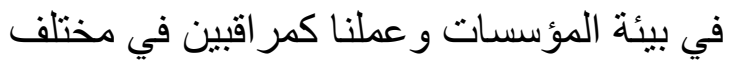
الأنشطة التي نفذت ولاحظنا كلّ برنامج في في روضة الأطفال نور الأنصار باندونج ليحصل على البيانات عن برنماج المعهد أكملا.

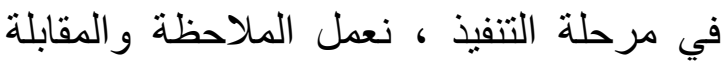
مباشرة. يتم ذللك أو لاً عن طريق تحئ تحديد المخبر الرئيسي ، وهو رئيس مؤسسة مدينة المختار (يوسف علي تنطاوي الحاج الماجستير) حول تاريخ إقامة روضة تلألة الأطفال نور الماجي الأنصار

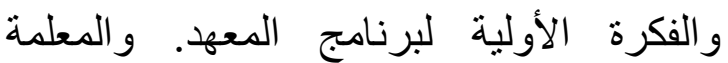
المشاركة في هذا البرنامج هي أجينج أيو باكتي الحاج ليسانس. وفي المرحلة النهائية وهي الإنجاز ، نعمل تحليل البيانات بمر احل توحيد البيانات وتصنيفها وتفسير ها بحيث تم تحقيق درجة الثقة في هذات 
البحث. يتم تفسير هذه البيانات من خلال تقديم

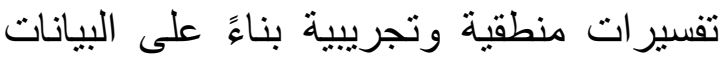

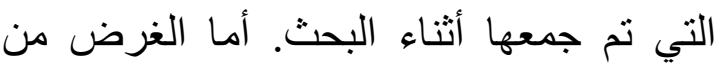
تفسير هذه البيانات هو مجرد وصف التفاء ، أي أن أن نقبله باستخدام نظرية وتصميم إدارة مختبر

$$
\text { العلوم في المدرسة. }
$$

\section{نتائج البحث ومناقشتها}

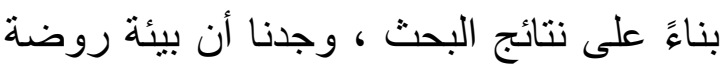
الأطفال نور الأنصار تضمن حقًا سلامة سكان

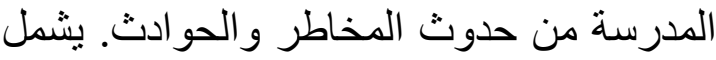
أمن روضة الأطفال نور الأنصار بيئة مدرسية مريحة مباني الددارس و الفصول الدراسية الدية و المكتب و المكتبة ومعدات و إمدادات الملاعب المانب و الساحة) ، بالإضافة إلى الساكنين المحليين المتناغمين. يحاول كل المجتمع الأكاديمي داخل

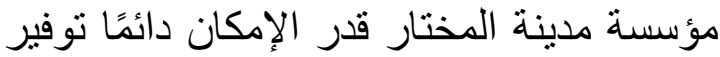
الأمن وحماية المدرسة من جميع الأشياء السيئة الائة

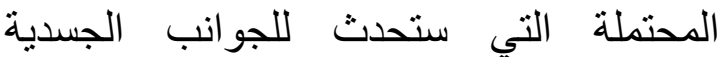
والنفسية لساكنين المدرسة من خلال تشكيل

$$
\text { فريق أمن المدرسة. }
$$

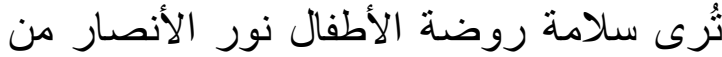

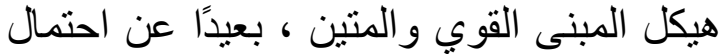

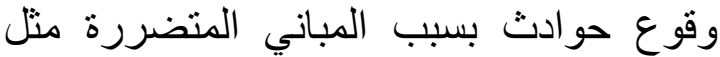
الأجسام المنساقطة ، بما في ذلك المواد المباد الخطرة

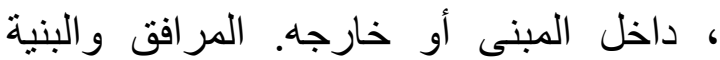

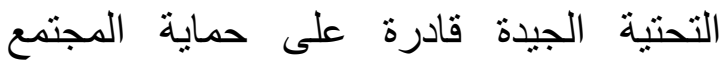
الأكاديمي و البيئة المحيطة من مخاطرة الكرة

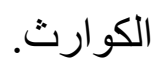

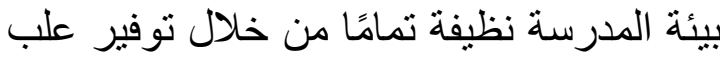
القمامة ونقلها عمال النظافة إلى موقع التخلص

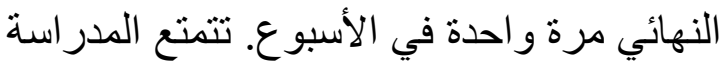
بييئة نظيفة وصحية وممتعة. المو اصفات الاتهية البيئية

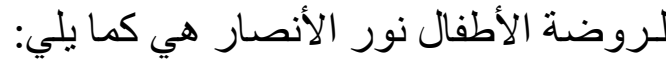
1. ظروف الفصل آمنة ومريحة وو اسعة الأهي
2. مجال الأنشطة الخارجية منل الرياضة

$$
\text { و التندريب اللامنهجي }
$$

3. المقصف مريح ويوفر طعاما نظيفا 4. مراحيض ذات مصادر كافية للمياه النظيفة 5. 5. 5 التهوية و الإضـاءة الكافية 6. إنشاء منطقة خالية من التناخين برنامج روضة الأطفال نور الأنصار على اللى أساس المعهل الإسلامي 1. تخطيط برنامج المعهد الإسلامي للأطفال المبكر في روضة الأطفال نور الأنصار منذ إقامتها ، تم تصنيع روضة الأطفال

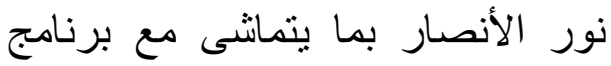
المعهد الإسلامي الحالي. لذللك ، تنتو افق التق أهداف روضة الأطفال الهال نور الأنصار

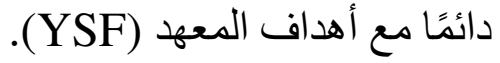

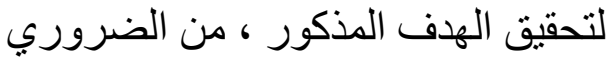

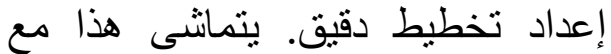
رأي سنجايا (2008) بأن التخطيط هو اتخاذ قرارات بشأن ما يجب القيان القيام به به لتحقيق الأهداف. يجب أن تبدأ عملية

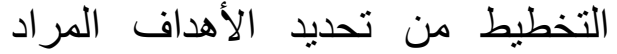
تحقيقها من خلال تحليل الاحتياجات وتحديد الخطوات التي يجب اتخاذها من أجل تحقيق هذه الأهداف. النتائج عند إجراء البحث ، التهاء ، لتحقيق

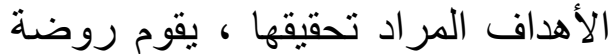
الأطفال نور الأنصار بما يلي: تحديد الطيد روضيد فريق تطوير المحتوى المحلي ، وتحديد

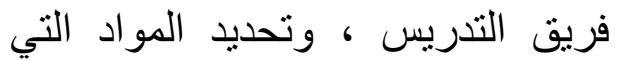

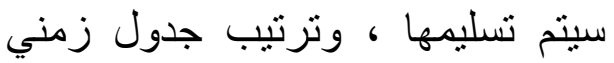
لأنشطة التدريب. يوضح الجدول 4.1 تركيبة المواد الخاصة بأنثطة برنامجة التامجة المدرسة الداخلية الإسلامية. وأما في 
الجدول 4.2 يتم تقديم الجدول الزمني لأنشطة التدريب.

\section{الجدول 4.1}

مادة نشاط التدميز

\begin{tabular}{|c|c|c|}
\hline 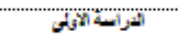 & 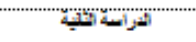 & 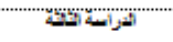 \\
\hline 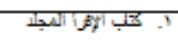 & , . & 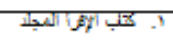 \\
\hline اיأون & الثائى & الئت \\
\hline r. . سردة النلن & r. سردة اللبب & ז. س سرة النصر \\
\hline ז... سردة القز & ז. . سردة الكونز & T- س سرة الساعون \\
\hline أ. سردة الإخلاص & 4. سودة الكلفون & 4. سودة ترين \\
\hline 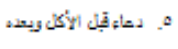 & 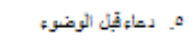 & هـ دثاء نذون السجد \\
\hline 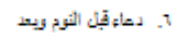 & 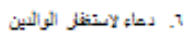 & 1. دماء خرقع السجد \\
\hline 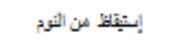 & & 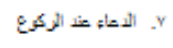 \\
\hline r y & & إJ \\
\hline الثرأسة المربعة & أثرأسة أذلانسة & أثراست أسلية \\
\hline 1 & ' & ' \\
\hline الزرابع & الخاس & السلس \\
\hline ب. سردة القن & r. سترة العتر & r. سترة العزركة \\
\hline r-. سردة الهبزة & ז. سودة التكتر & T. بـاء القوت \\
\hline أ. لدشاء السجود وجلوس & ك. دماء التئيل & أ. ابة الكربس \\
\hline بين سجنتين & 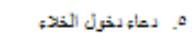 & مـ دـاء آثر الجلة \\
\hline ع. دهاء اللبن & وخرق نه & 1. لدهاء خير النبا \\
\hline 1. دياء نريت اللبنل & 3. دماء بيد الوضو: & 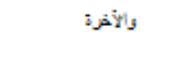 \\
\hline 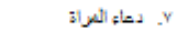 & & \\
\hline
\end{tabular}

المصدر : أرشيف روضة الأطفال نور الأنصار

\section{الجدول 4.2}

الجدول الزمني لأنشطة برنامج الممارسة

\begin{tabular}{|c|c|c|}
\hline أجئن & 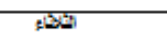 & المزيفاء \\
\hline 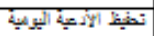 & تهنيط أسماء أم الحسذى & كابن مروف الهجبية \\
\hline 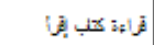 & ترأ & 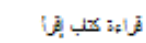 \\
\hline لخنيس & 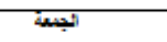 & \\
\hline نهيظ السورة القصيزة & ثريب الصلاة & \\
\hline | & 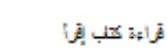 & \\
\hline 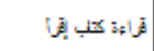 & & \\
\hline
\end{tabular}

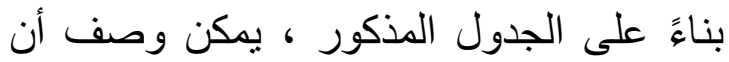

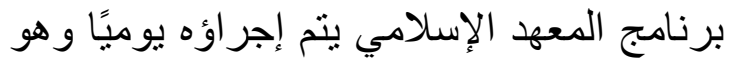

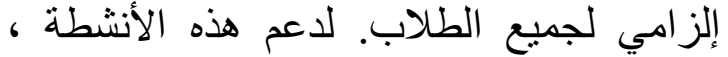

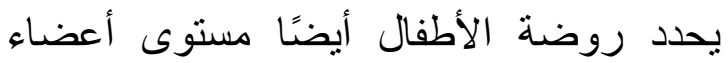
هيئة التدريس. يجب على على المعلمين أن يكونوا قادرين على قر اءة القرآن وكتابته جيدًا ، وحفظ لئل الجزء 30 دن القرآن والحديث اليومي.

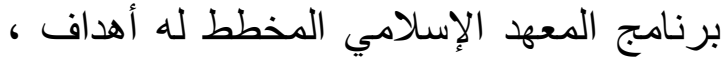

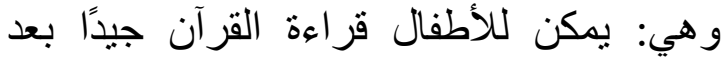

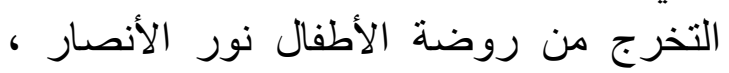
و الأطفال لديهم وعي جيد بالصلاة ، ويحفظون الصنال

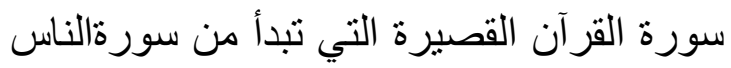
إلى سورة القارعة ، ويؤدون الصلاة بشكل منظم ومنظم بطريقة متسلسلة (FE ، (AYB).

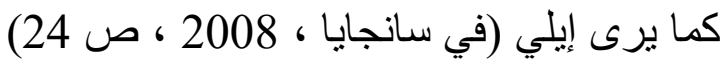
أن التخطبط هو في الأساس عملية وطريقة تفكير يمكن أن تساعد في خلق النتائج المتوقعة.

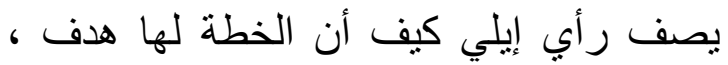
باستخدام كلمة "نتائج" يجب تحقيقها في تحديد الخطة.

2. تنفيذ برنامج المعهد الإسلامي للأطفال المبكر في روضة الأطفال نور الأنصار

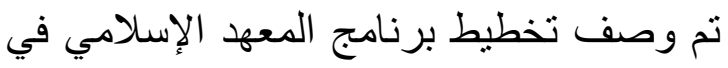
مرحلة الأطفال المبكر قبل هذا. في هذا البرنامج ، ليس فقط التخطيط ولكن أيضًا التفيذ ولفئ النتائج. يعد تنفيذ برنامج المعهد الإسلامي للأطفال 
المبكر في روضة الأطفال نور الأنصار شكلاً من أنشكال تنفيذ التخطيط التي تم وضعها.

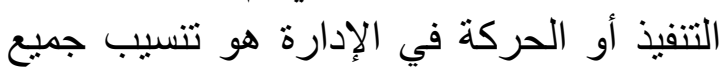

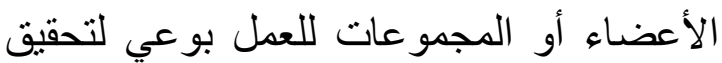
الأهداف التي تم إعدادها ( Ramayulis ) 2012 ، ص الف 381). روضة الأطفال نور الأنصار تضع المعلمين وفقًا لقدراتهم. لأن الأن

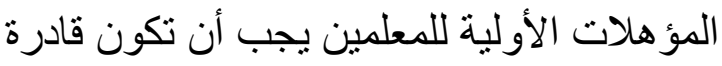

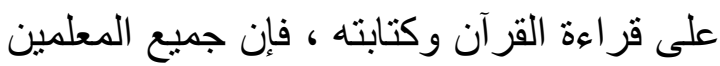

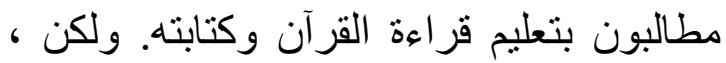

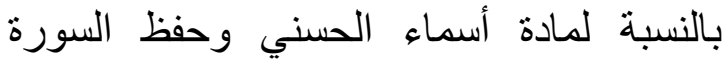
القصيرة والأدعية اليومية فقد تم ترتيب النيب لللمقدمين بشكل مختلف. لحفظ السورة القصيرة والأحاديث النبوية ، كان معلمته هي أجينج أيو الكيرة

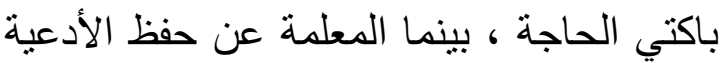

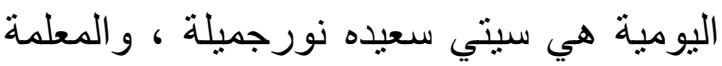
لمادة أسماء الحسنى هي أيو بونجا لبيتاري.

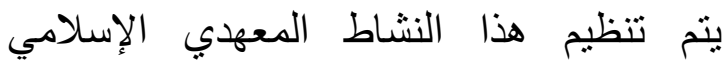
ومر اقبته من قبل رئيس روضة الأطفال ورئيس الإنيس

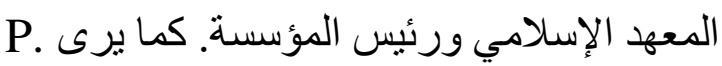
Siagian

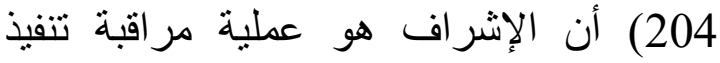

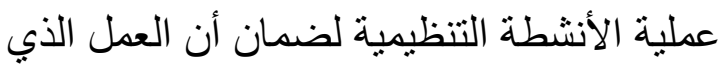
يتم تنفيذه يسير وفقًا لخطة محددة مسبقًا. الآباء و الأوصياء يريدون لأبنائهم وبناتهم الذين

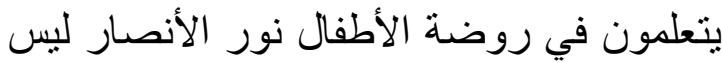

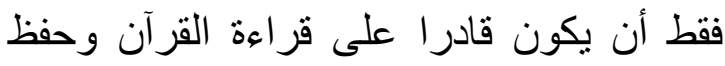

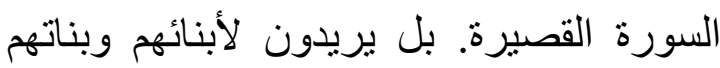

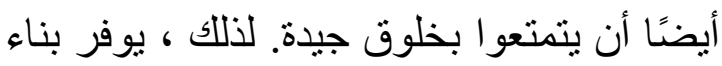

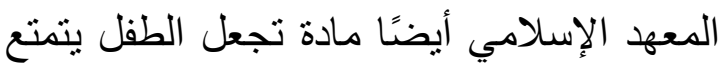

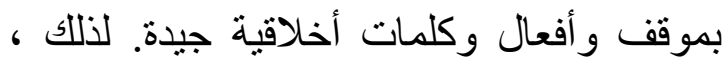
يقدم المعلمون كل يوم أمثلة ويعلمون كيفية التصرف و التكلم بالكلمات الطيبة. والدرس الذي أوصى به النبي محمد ــ صلى الله

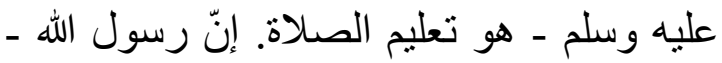

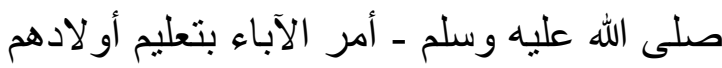

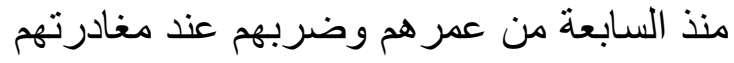

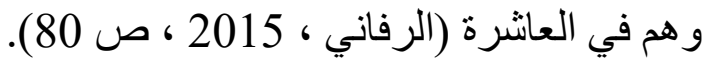

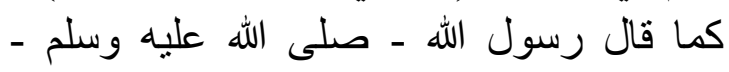

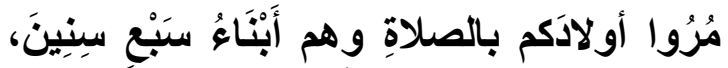

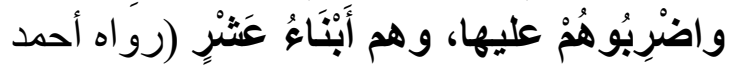
و وأبو داود و الحكيم). يتعلم جميع طلاب روضة والدة الأطفال نور الأنصار أدعية الصلاة وممارستهم في أنشطة التعود كل بلانل

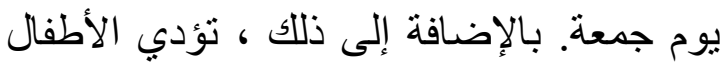

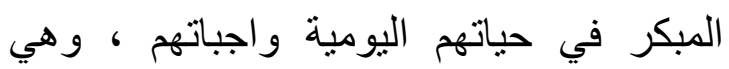
الصلاة خمس مر ات مع و الديهم. بالإضافة إلى المواد المعهدي الإسلامي التي

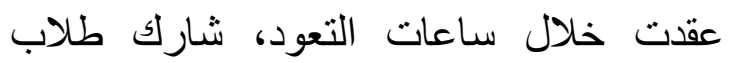

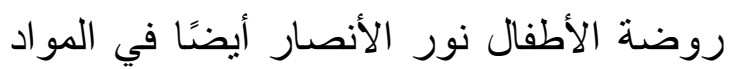

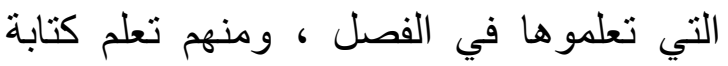
الحروف الهجائية والأرقام العربية وإيداع وايداع السورة القصيرة وأسماء الحسنى والأدية ولئة اليومية لمعلم فصلهم. عندما يحدث التدريب ، هناك أيضًا عملية تعلم

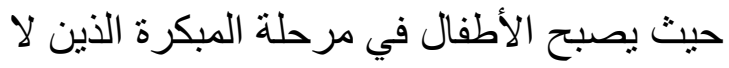

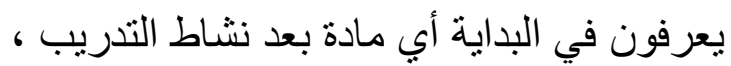
مدركين. و هذا يتمانشى مع ما ذكره فريق فئ تطوير

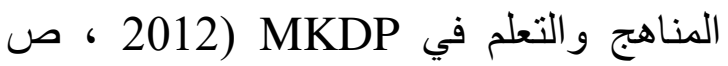
124) "هذا التعلم هو نشاط مقصود وينفذه

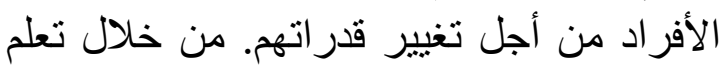

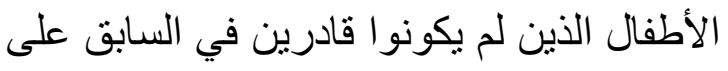
فعل شيء ما ، يصبحون قادرين على الثين القيام

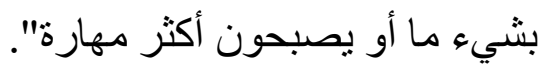
تشهـ الأطفال المبكر حاليًَا تطورًا في كل منهارة" تشمل التطور ات التي تحدث في مرحلة الأطفال

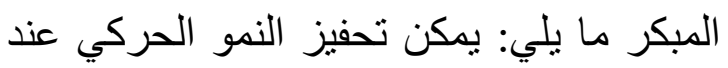

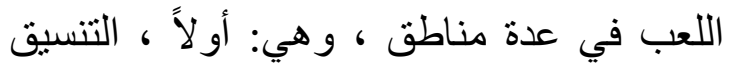

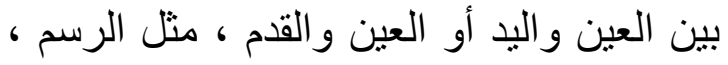

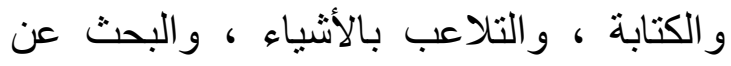

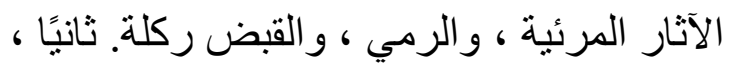

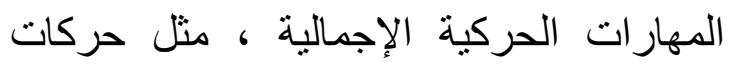




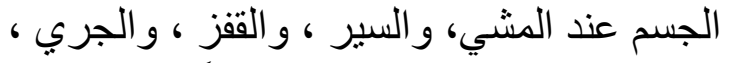

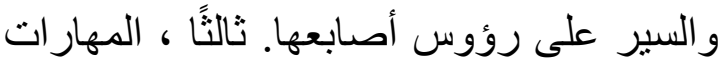

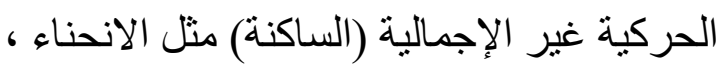

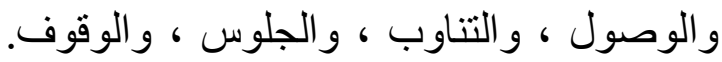

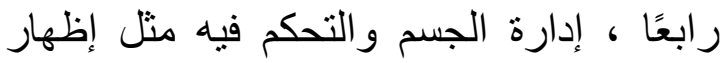

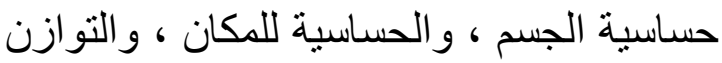

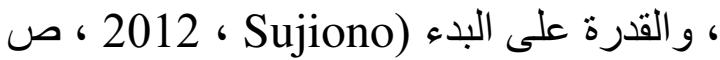

التطور الحركي الذي يحدث هو: أولا ، التنسيق بين العين واليد عند الكتابة. ثانيًا ، المهارات التات التهات

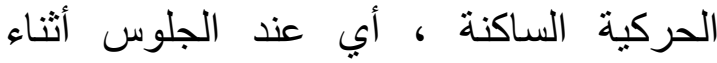

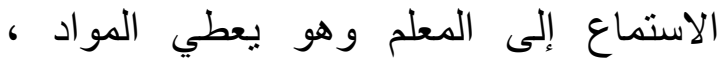

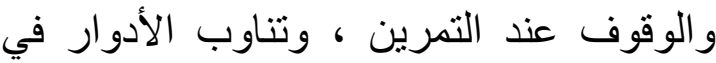

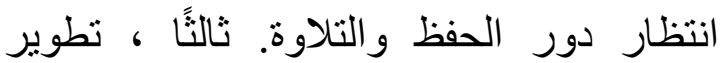
التحكم ، أي تجرؤ الطلاب على البداء في إعطاء التهاء

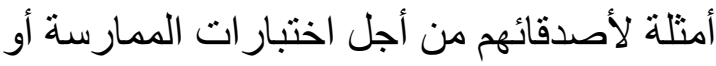

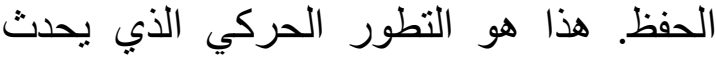
عندما ينت تشغيل برنامج المعهد الإسلامي.

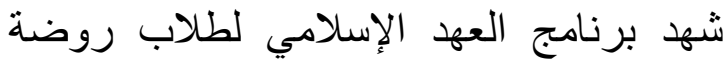

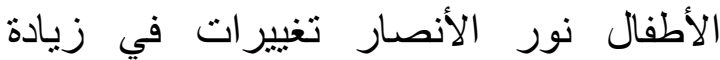

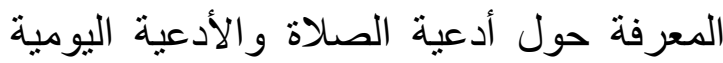

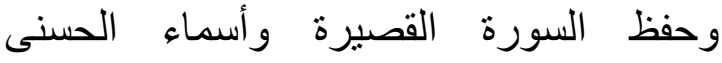

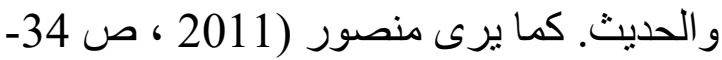

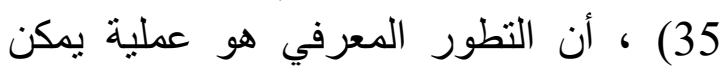
للأفراد من خلالها تحسين قدر اتهم و استخدام

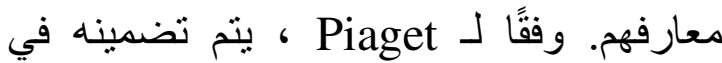
مرحلة ما قبل التثغيل (من 2 إلى 7 سنوات) حيث يبدأ الأطفال في التقديم بالكلمات و الصور.

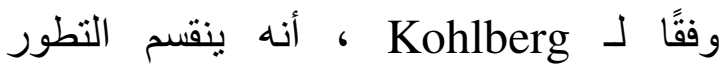

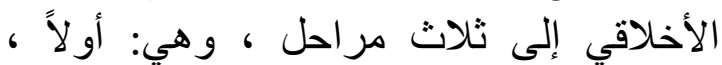

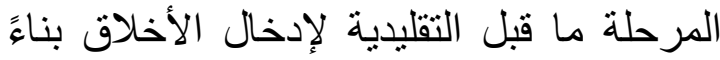

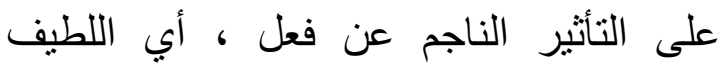

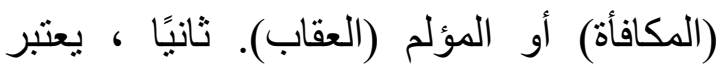

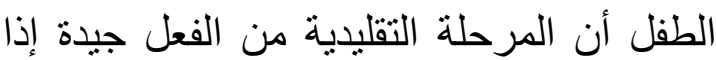

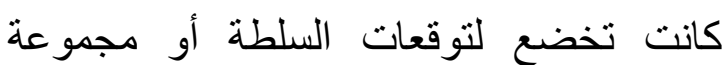
الأقران. ثالثًا ، لا يُنظر إلى مرحلة ما بعد الِّل
التقليدية لقو اعد ومؤسسات المجتمع على أنها الهدف النهائي ، ولكنها ضرورية كموضوع. يخضع الأطفال للقو اعد لتجنب عقاب الضمير (262-261) 2011، Desmita) كل يوم الجمعة ، يودع طلاب نور الأنصار

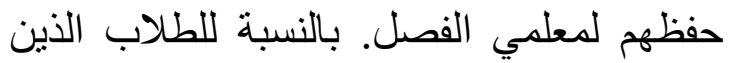

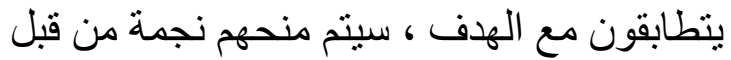
المعلم. ولكن بالنسبة للطلاب الذين ينالاعبون عند إيداع حفظهم ، سيتم منحهم عقوبة لتكر لتكرار

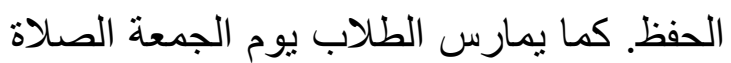

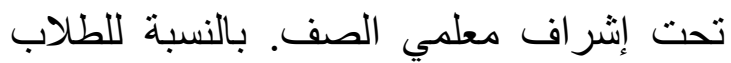
الذين يتجولون أثناء تتفيذ هذه الممارسة ، يُعاقبون بتكر ار صلاتهم. الطريقة عبارة عن مجموارة عنة من الطرق والمسارات التي يقوم بها المعلمون في عملية التعلم بحيث يحقق الطلاب أهداف التعلم أو يتقن الكفاءات المصاغة في المواد. تشمل طرق التهل

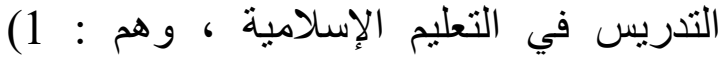

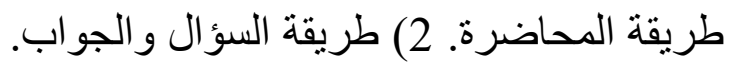

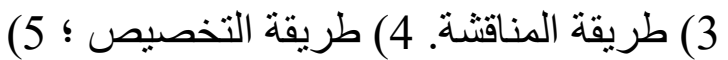
طريقة العرض. 6 6) الطريقة التجريبية

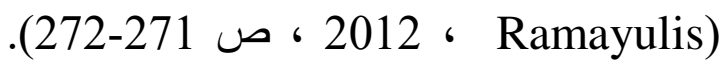
في وقت إعطاء المادة ، استخدم المعلمون

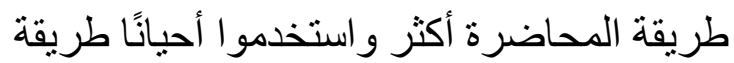
السؤال و الجواب. بالإضافة إلى استخدام طريقة

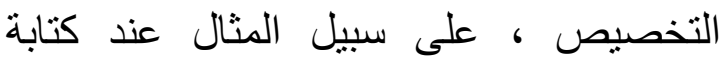
الحروف الهجائية. طريقة أخرى مستخدمة في هذا البرنامج هي الإندائ طريقة الإيداع ، حيث يقوم الطلاب بايداع الحفظ. وفي الوقت نفسه عند ممارسة الصلاة الوبلة والوضوء بالطرق العملية. ينم استخدام طريقة سوروجان عند تعلم "إقر اء" وقراءة القرآنا آن.

3. نتائج وتقييم برنامج المعهد الإسلامي للأطفال المبكر في روضة فئمن الأطفال نور الأناهي الأنصار 
وضع برنامج المعهد الإسلامي للأطفال المبكر

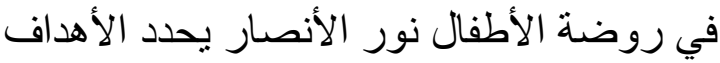
التي يجب تحقيقها الطلاب. فلحفظ السورة القصيرة هي تبدأ من سورة الفاتحة إلى سورة

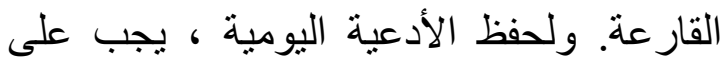
الطلاب حفظ 14 أدعية يومية ، و 10 أحاديث

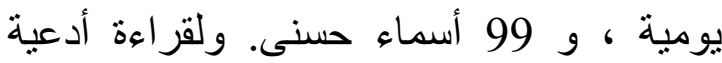
الصلاة هي تبدأ من تكبيرة الإحرام حتى دعاء ولى ولهاء

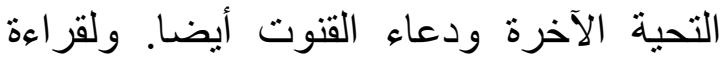

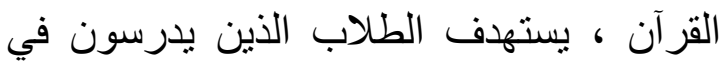

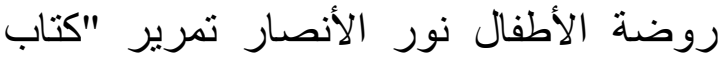
الإقرأ المجلد الأول" إلى "كتاب الإقراء المجلد

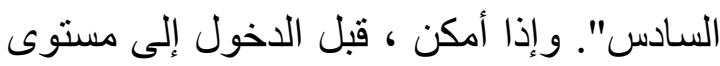
، SD / MI

جيدا صحيحا. بالإضافة إلى الأهداف المذكورة ، فإن الغرض

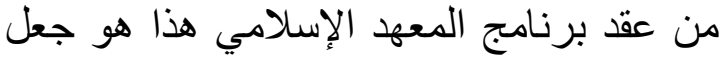

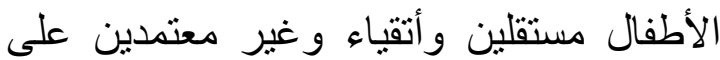
و الديهم. ولذلك ، يتم تعليم الطلاب أيضًا إكمال وعندين و اجباتهم الخاصة من الإعداد إلى الانتهاء. و أما شكل التقييم الذي يتم إجر اؤه لهذا البرنامج الأناء التهاء

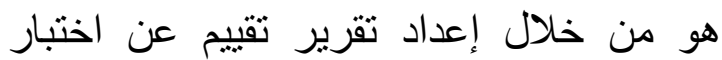
شفهي و عملي. يتم إضافة بطاقة التقرير أيضًا

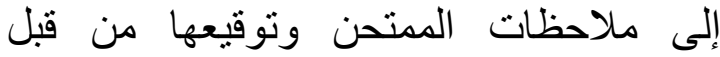
الممتحن ورئيس المدرسة ومعلم الفصل و وأباء الطلاب أو أوليائهم. سيتم منح الطلاب الذين يجتازون الاختبار الثفوي جوائز كتشجيع. يتم قياس نجاح هذا البرنامج من خلارل عملية

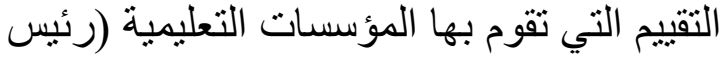
المدرسة). يعتمد التقييم الذي أجرته المدرسة

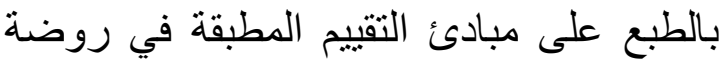
الأطفال نور الأنصار . فيما يلي تقرئ الأيم عن نتائج

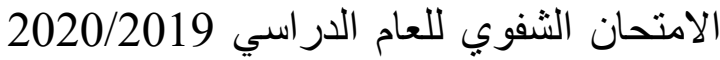
التي تبدأ من 22 يوليو 2019.

\section{الجدول 4.3}

تلخيص نتائج الإمتحان الثفوي
القترة يوليو ـ أكتوبر 2019

\begin{tabular}{|c|c|c|c|c|c|c|}
\hline القصال & أنرل مبل & الثناتي & الثراك & الترابع & التخلس & السفس مجل \\
\hline \multicolumn{7}{|l|}{ A } \\
\hline$B 1$ & 9 & $r$ & & T & & \\
\hline B2 & A & $\varepsilon$ & & & & \\
\hline B3 & & & & & & \\
\hline & & & & & & \\
\hline
\end{tabular}

المصدر : أرشيف روضة الأطفال نور الأنصار

تم تشغيل برنامج المعهد الإسلامي هذا منذ إقامة روضة الأطفال نور الأنصار في عام 2016. بحيث يكون بعض خريجي روضة الأطفال نور الأهفال نور

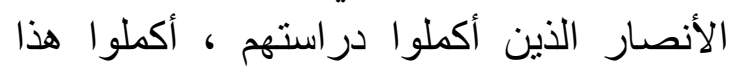
البرنامج أيضا ، وحضروا لبرنامج التخرج التهرج

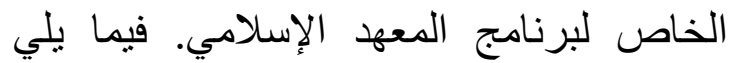
تلخيص الطلاب الذين أكملوا برنامج المعهد

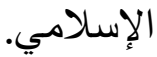

\section{الجدول 4.4}

\begin{tabular}{|c|c|}
\hline عامدراسلي & דיםهع \\
\hline$r+1 \% / r+1 v$ & $r$ \\
\hline$r+Q V / r+1 A$ & $r$ \\
\hline$r \cdot 1 / r+19$ & $r$ \\
\hline
\end{tabular}

المصدر : أرشيف روضة الأطفال نور الأنصار

وجود هذا البرنامج يغير الطلاب من حيث الإدر الك / المعرفة. ولو كانت لم تنجح كلها كما هو في غرض البرنامج، لأنّ الأطفال لإيهم قدرات مختلفة ويختبرون دعمًا أبويًا مختلفًا.

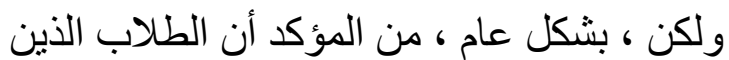

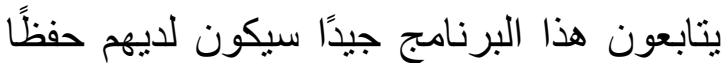

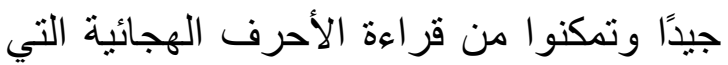
تم ربطها وفقًا لقواعد القراءة. وإن لمداعة لم يكتمل 100 بالمائة من هذا البرنامج. 


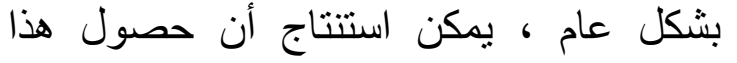

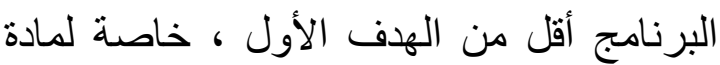

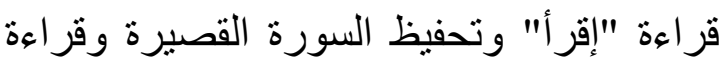

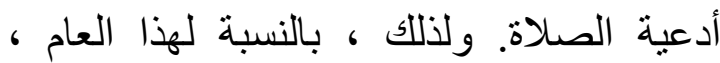

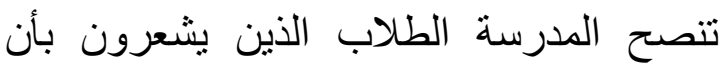
لايهم أوجه قصور بمتابعة برنامج الديانة الذي لئي

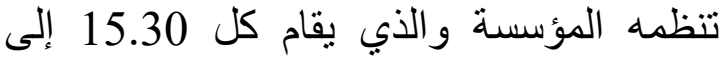

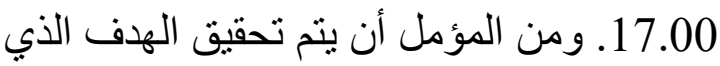

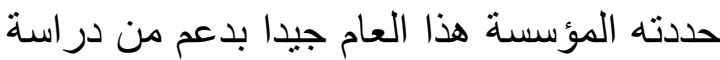

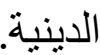

الخاتمة الخات

يمكن الاستتناج أن تخطيط برنامج المعرد الإسلامي للأطفال المبكرة في روضة الأنس الأطفال

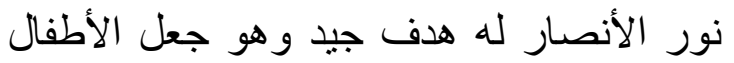

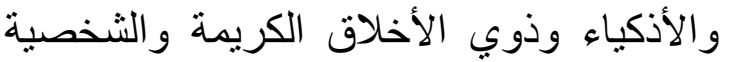

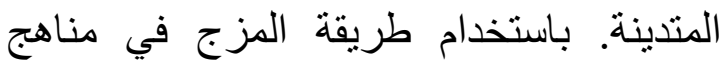

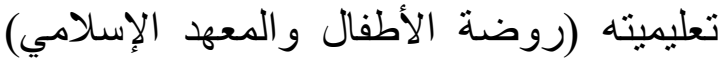

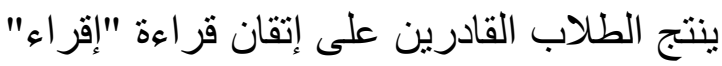
وحفظ السورة القصيرة. وتتمثل الإستراتيجية

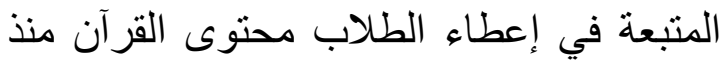

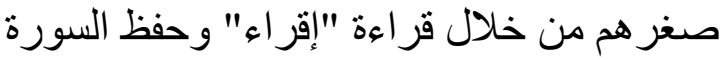
القصيرة. وبجانب ذلك ، الطلاب يؤدون الأدعية

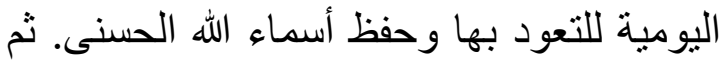

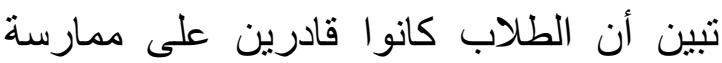

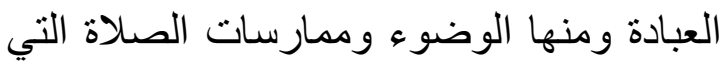

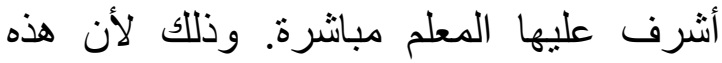
المواد قد تمت تصميمها وجدولتها قبل ولت ولتان طويل من بدء العام الدر اسي الجديد.

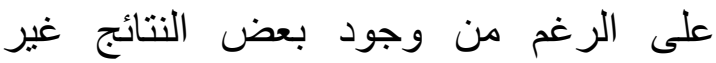

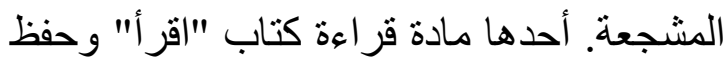

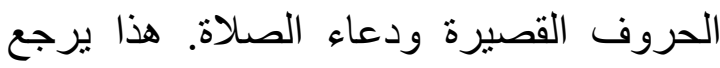

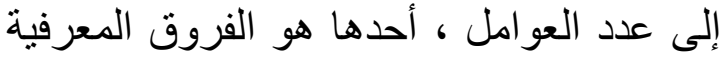

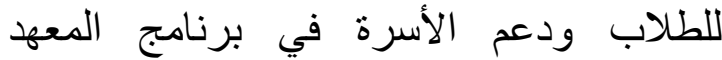
الإسلامي هذا. تعتبر نتائج هذا التقييم بمثابة
مدخلات للمؤسسة لتحسين جودة التعليم و التعلم

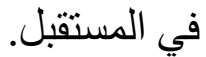
يتم دائمًا الإشر اف على تنفيذ نشاط المعهدي هذا أو التحكم فيه مباشرة من قبل رئيس روضئ الأطفال ورئيس المعهد الإسلامي ورئيس ونئيس المؤسسة. يقوم الطلاب بايداع الحفظ دوريا وكل الطئل

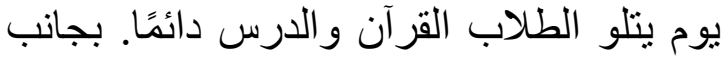
ذللك ، يتعلم الطلاب كتابة الحروف الهجابئية كلئ لئل يوم أربعاء. في الممارسة العملية، يستخدم لئلية المعلم طريقة تتكيف مع المو اد المقدمة.

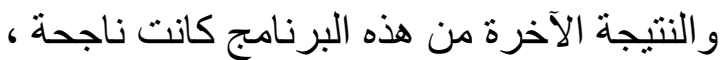

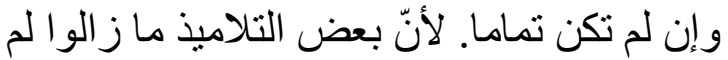

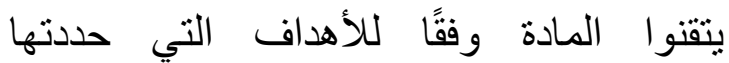
المدرسة. بسبب ذللك ، توفر المعهد الإسلامي لإهي بديلاً لهذهة المشكلة من خلال مطالبة الطلاب بتعلم إضافية. من المأمول أن يتم تطبيق تربية المبلة

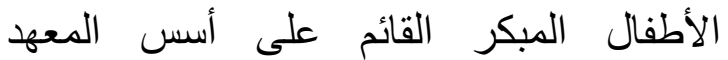
الإسلامي على نطاق واسع في المستقبل. فضلاً

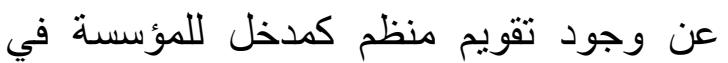
تحسين جودة التقويم التربوي.

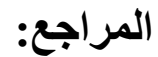

Badrudin. (2013). Manajemen Peserta Didik. Jakarta: PT INDEKS (2014). Dasar-Dasar Manajemen. Bandung: Alfabeta.

Creswell, John W. (2013). Research Design Pendekatan Kualitatif, Kuantitatif, dan Mixed (Edisi Ketiga). Yogyakarta: PUSTAKA PELAJAR

Darajat, Z. (2010). Ilmu Jiwa Agama. Jakarta : Bulan Bintang

Desmita. ( 2011). Psikologi Perkembangan Peserta Didik. Bandung: Rosda

Hawadi, L. F. (2012). Pedoman Pendidikan Karakter Pada Pendidikan Anak Usia Dini. Jakarta: Direktorat Pembinaan 


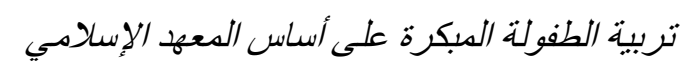

Pendidikan Anak Usia Dini, Siagian, S.P. (1982). Filsafat Administrasi, Kementrian Pendidikan Nasional. Jakarta: Gunung Agung Hasibuan, Malayu S.P. (2011): Manajemen: Dasar, Pengertian dan Masalah (Edisi Revisi), Jakarta: Bumi Aksara Cetakan ke-9

https://www.kemenpppa.go.id/index.php/ page/ read/29/2738/angkakekerasan-terhadap-anak-tinggi-dimasa-pandemi-kemen-pppasosialisasikan-protokol-perlindungananak

Mansur. (2011). Pendidikan Anak Usia Dini Dalam Islam. Yogyakarta: Pustaka Pelajar

Moleong, Lexy J. (2004). Metodologi Penelitian Kualitatif (Edisi Revisi). Bandung: PT. Remaja Rosdakarya

Mulyasa. (2012). Manajemen PAUD. Bandung: Remaja Rosdakarya

Muntomimah, S. (2017). MODEL PENDIDIKANKARAKTER ANAK USIA DINI DI PONDOK PESANTREN AL HIKAM KOTA MALANG. JIP, 43.

Nasih, A.M., \& Kholidah, L.N. (2013). Metode dan Teknik Pembelajaran Pendidikan Agama Islam. Yogyakarta: Pustaka Pelajar

Ramayulis. (2012). Ilmu Pendidikan Islam. Jakarta: Kalam Mulia

Rifani, N.K. (2015). Dahsyatnya Mendidik Anak Gaya Rasulullah.Yogyakarta: Semesta Hikmah

Sagala, S (2009). Administrasi Pendidikan Kontemporer. Bandung: Alfabeta

Satori, D., \& Komariyah, A.(2013). Metodologi Penelitian Kualitatif. Bandung: Alfabeta

Shihab, M.Q. (2008). Tafsir Al-Misbah, Kesan dan Keserasian Al-Quran Vol 3. Tangerang: Lentera Hati 